\title{
Os magistrados e as monarquias ibéricas no século XVIII
}

\author{
The judges and the iberian monarchies in the eighteenth century. \\ Paulo Fillipy de Souza Conti \\ https://orcid.org/0000-0002-7545-2584 \\ Universidade Federal de Pernambuco
}

\begin{abstract}
Resumo: A historiografia brasileira e estrangeira tem dado destaque cada vez maior aos estudos comparativos. E, no que diz respeito aos reinos de Portugal e Castela, as aproximações e diferenças podem avançar pelas mais diversas áreas. $O$ compartilhamento de uma cultura letrada entre os reinos ou a existência de uma cultura letrada propriamente ibérica caracterizam, por exemplo, as leis e agentes de justiça para ambos os contextos. No entanto, ao longo do século XVIII pode-se observar mudanças na relação que tinham os profissionais da justiça com as casas reinantes. Enquanto assistimos em Portugal ao avanço dos magistrados sobre os cargos mais altos do serviço régio, por outro lado, os castelhanos passaram a afastar e diminuir irreversivelmente a nomeação dos chamados colegiales mayores. $\mathrm{O}$ espaço deixado vago pela elite econômica e letrada espanhola foi sendo rapidamente ocupado por outra categoria profissional: os advogados. O que pretendemos oferecer como contribuição para essa discussão historiográfica é uma tentativa de observar esses dois fenômenos em paralelo. Ao fazer apontamentos que vão desde refletir o que aproxima e o que afasta as Coroas de determinadas categorias profissionais até o papel das universidades nesse jogo.
\end{abstract}

Palavras-chave: Monarquias Ibéricas. Magistrados. Século XVIII.

Abstract: The Brazilian and foreign historiography has given increasing importance to comparative studies. And regarding the kingdoms of Castile and Portugal, approaches and differences can advance through several areas. The sharing of a literate culture between the realms or the existence of a properly Iberian literate culture, for example, characterize the laws and agents of justice for both contexts. However, throughout the $18^{\text {th }}$ century can be observed changes in the relationship they had legal practitioners with the reigning houses. As we watch in Portugal to the advancement of judges on the highest offices of the royal service, on the other hand, the Spaniards began to pull away and irreversibly diminish the appointment of colegiales mayores. The space left vacant by the Spanish economic and literate elite was quickly occupied by another professional category: the lawyers. What we intend to offer as a contribution to this historiographical discussion is an attempt to observe these two phenomena in parallel. In making notes that range from reflecting what draws close and what moves Crowns from certain professional categories to the role of universities in that matter.

Keywords: Iberian monarchies. Judges. $18^{\text {th }}$ century.

\section{Uma cultura letrada ibérica}

Não é absolutamente uma novidade historiográfica tratarmos do compartilhamento de uma tradição jurídica comum entre os reinos ibéricos. No livro Como os juristas viam o mundo, o historiador e jurista português António Manuel Hespanha faz uma provocação historiográfica ao tratar a visão jurídica do Antigo Regime

Esta obra está licenciada sob uma Creative Commons - Atribuição 4.0 Internacional 
como típica da Europa "latina". Para evitar problemas interpretativos, o autor explicita na sequência as razões que conduziram o seu pensamento nesse sentido. Diz ele não acreditar em um "espírito latino" ou em uma "cultura latina". Tampouco considera que esse fenômeno pode ser atribuído aos diferentes panoramas religiosos entre "Sul" e "Norte" da Europa após a reforma protestante. Para Hespanha, o cerne da questão estava de fato no uso e comunicação do corpus literário. Mesmo antes da cisão religiosa, os juristas do "Sul" discutiam entre si, enquanto os do "Norte" (leia-se alemães, holandeses e ingleses) não tinham uma literatura jurídica muito expressiva. Logo, havia um corpus literário comum entre os juristas ibéricos, italianos e até mesmo franceses, na primeira época moderna. "A identidade 'do Sul' é antes uma identidade induzida por um círculo de comunicação" (HESPANHA, 2015, p. 19801).

$\mathrm{E}$ o que por vezes nos escapa é exatamente perceber que esse compartilhamento foi um fenômeno para além dos limites de Espanha e Portugal. $O$ conjunto de textos produzidos por eles tem no chamado ius commune (Direito Comum) o maior peso para as diretrizes da justiça no que se refere à formação de um código de convivência que independe das leis dos reinos. Ele era, na realidade, "uma constelação aberta e flexível de ordens cuja arquitetura só podia ser fixada em face de um caso concreto" (HESPANHA, 2006, p. 105). O que por si garante a sua originalidade e afasta a ideia de uma possível preservação "imaculada" dos textos do Direito Romano. Ainda assim, tem a sua temporalidade e localidade bem definidas, tendo adquirido forma $\mathrm{e}$ conteúdo na região italiana com o florescimento das universidades do século XII. Isso significa dizer que o chamado Direito Comum é, na realidade, reflexo de uma forma social de ver o mundo de algumas sociedades do medievo, que se estende e vai sofrendo adaptações com o passar dos anos e diante da realidade das comunidades. Localizar no tempo e no espaço esse acontecimento nos permite, além do que já foi apontado, evitar entende-lo dentro dos parâmetros modernos (GROSSI, 2014, p. 9-12).

Voltemos então a falar sobre o compartilhamento do corpus literário entre os Reinos latinos, tema abordado no início do artigo. O ius commune, nessa seara foi, sem sombra de dúvida, o mais partilhado. Mas, baseado em leitura de Malagón Barceló, Víctor Tau Anzoátegui (2016, p. 16) diz que as obras de jurisprudência espanholas alcançaram nos séculos XVI e XVII a "Italia, Francia, Inglaterra y Polonia, junto con la presencia de profesores españoles en universidades de esos países y con la recepción en España de algunas doctrinas extranjeras". A ideia então corrente era de que nessas outras localidades era mais simples conseguir boas posições (ALONSO ROMERO, 2012, p. 464). Não temos informação semelhante para os professores portugueses, outrossim, não é improvável que alguns deles também tenham seguido caminho parecido. O que nos chama especial atenção na informação dada por Anzoátegui é que o conteúdo presente nessa troca era o direito dos reinos.

Para tal, assume que os livros de Direito escritos por juristas tinham boa circulação. Eram encontrados nas periferias do Reino e do Império, garantindo assim, "o conhecimento da tradição jurídica letrada nos confins mais afastados, mesmo independentemente de aí existirem juristas". Nos centros urbanos eram ainda mais comuns. O que não significa que todos os magistrados puderam contar com grandes bibliotecas pessoais. Hespanha diz que a lista de livros de referência para o trabalho dos juristas e juízes era curta e, ainda menor era o número de obras de fato utilizadas. Na maioria das vezes, o acesso a essas obras só era possível em instituições com boas bibliotecas. A posse pessoal passava pelas dificuldades do valor, transporte e fragilidade das obras (HESPANHA, 2015, p. 365-366). 
Informação que vai de encontro ao que Víctor Tau Anzoátegui (2016, p. 15) apresenta para o mundo hispânico:

La imagen literaria o pictórica del buen jurista estaba asociada a un conjunto numeroso y selecto de libros. Se solía presentar a los letrados civiles y canónicos hispanos rodeados de libros, en una clara alusión a que éstos constituían la más necesaria y decorosa compañía para enaltecer su figura. No existiendo por entonces bibliotecas públicas accesibles, era preciso que los letrados, y sobre todos los jueces superiores, poseyeran buenas bibliotecas de donde pudieran servirse para el desempeño de sus tareas.

Anzoátegui fala bastante sobre a imagem associada, mas, quando traz a informação sobre as bibliotecas, vai de encontro ao exposto por Hespanha. Considerando a posse de livros, fosse pela existência de grandes bibliotecas pessoais ou pela manutenção de poucos volumes fundamentais para o serviço, somos induzidos a pensar na continuidade dos estudos após a formação e a necessidade de consultar os códigos para basear as sentenças. No que se refere ao ambiente universitário, temos no caso português um espaço unificado para a formação, a Universidade de Coimbra, onde o curso era muito mais do que um processo de formação intelectual. $A$ instituição tinha a responsabilidade de proporcionar, principalmente, uma experiência de socialização que levasse ao senso comum entre os alunos de lealdade e obediência ao monarca. Pois, quando inseridos no sistema, não eram funcionários civis, senão servidores do rei. Esta estreita ligação não impedia que decisões fossem tomadas em contrariedade aos desejos da Casa reinante e a favor dos interesses dos próprios magistrados (SCHWARTZ, 2011, p. 79-82). Se por um lado, Portugal centralizou a formação da maioria dos seus magistrados, por outro, os distribuiu por praças distantes e distintas. Ou seja, buscou-se um processo formativo homogêneo para que pudessem servir em espaços heterogêneos.

Ao contrário do que acontecia em Portugal, não houve centralização da formação universitária no mundo espanhol. Havia sim padrões ou costumes semelhantes nas universidades, por ter a Universidade de Salamanca servido como exemplo, antes e depois do seu Plano de Estudos de 1771. A crítica do século XVIII asseverava uma situação bastante diversa. O privilégio dado em Salamanca era aos exercícios práticos, mas não excluía nenhuma outra forma de pensar as leis, diz María Paz Alonso Romero. Para ela, a competência formativa desejada pela Coroa estava relacionada ao conhecimento das Leis do Reino, matéria garantida pelo cumprimento total do tempo de formação (ALONSO ROMERO, 2012, p. 342-343).

Sin embargo, hacia la segunda mitad del siglo XVIII el antiguo modelo [de formación] tenía todavía una notoria presencia, en coexistencia con las nuevas ideas, como ocurrió en Salamanca con ciertas prácticas universitarias y con la adopción del nuevo Plan de Estudios de 1771. En Nueva España, por ejemplo, se mantenía como requisito para acreditar las dotes de un catedrático su modo de disertar en el aula a la antigua usanza sobre la base de los textos canónicos y civiles. (ANZOÁTEGUI, 2016, p. 14)

Mesmo com o novo plano de estudos, costumes mais antigos foram mantidos, o que mostra a força das permanências dos costumes do Antigo Regime ainda em finais do século XVIII. O desejo de mudar os planos de ensino, tanto em Salamanca como em Coimbra, além de passar pela resistência de alguns professores e juristas, passava ainda pelo desafio de alterar a tradição jurídica e de acesso aos espaços de formação 
superior. Tais resistências e permanências, tem relação direta com o enraizamento de valores jurídicos que passaram a se confundir com a tradição jurídica dos reinos. E, por vezes, a ideia de anterioridade dos preceitos jurídicos ganhava força diante de um quadro completamente diferente. No século XVIII, por exemplo, mesmo com as reformas promovidas pelas Casas reinantes, buscou-se discursos de finais da Idade Média para justificar a adoção ou manutenção dos localismos.

Em Portugal, por exemplo, a lei do príncipe aparece esporadicamente na primeira metade do século XIII e ganha reforço na segunda metade, com Afonso III. Na Espanha, até mais ou menos a mesma época não havia unidade jurídica entre as regiões. A consolidação de um código mais vinculado ao rei parece ter sido obra de Afonso X, através da celebrada obra Las Siete Partidas, que tentou dar uniformidade às leis do Reino de Castela. Colocava ainda os nobres em posição privilegiada para o exercício de cargos na magistratura superior (jueces mayores), ao associar a linhagem com a incapacidade de errar, por ser o pudor um sinal de nobreza (VALLEJO, 1998, p. 28). Ainda assim, pelo seu caráter doutrinário, ela não foi imediatamente aceita pela tradição castelhana. Afinal de contas, a vinculação direta do poder político ao jurídico só pode ser vista de maneira crescente no século XIV. É quando o Direito passa não apenas a reafirmar a posição dos grupos reinantes, mas, na mesma medida, passa a ser "absolutizado" nas linhas dos códigos dos reinos ${ }^{1}$.

Ainda assim, nas Cortes de Alcalá, em 1348, onde e quando foi proibido o uso do Direito Comum, a ressalva do rei Afonso XI, para que em caso de dúvidas sobre a possibilidade de mudança nas leis fossem consultados os livros dos sábios antigos, deixou a proibição praticamente como letra morta. Até mesmo porque leis que vieram após a proscrição legal do Direito Comum nos tribunais acabaram reforçando o seu uso até o século XIX. A prática dos tribunais continuava sendo casuística e as permanências interpretativas comprometiam o caminhar em direção ao chamado Direito Pátrio (ALONSO ROMERO, 2012, p. 327-330). Questão que reflete muito mais os desejos das Casas reinantes do que a realidade. Afinal, é bastante simples de perceber que sob o plano legal dos reinos, havia uma efervescente pluralidade jurídica, ordens particulares, o que retoma, em termos de concepção, uma lógica antiga de entender o particular como superior (para aplicabilidade) em relação ao geral (HESPANHA, 2006, p. 102). Era, no final das contas, a sobrevivência modificada do "localismo jurídico".

Diante das permanências, houve forte crítica a capacidade formativa das universidades. Esta crítica está centrada no conceito de Direito adotado pelas universidades responsáveis pela formação dos letrados, a partir do século XVI, e no uso da Teologia nos tribunais do mundo hispânico. A historiadora Tamar Herzog informa que a maior parte dos letrados americanos tinha formação em Direito Civil e Canônico. Os que não tinham, costumeiramente, davam prioridade ao Direito Canônico, por acreditarem que era esse um conhecimento capaz de dar conta das obrigações espirituais e temporais. Por isso, não é surpresa que a tentativa por parte da monarquia castelhana de laicizar os tribunais tenha fracassado. Ora, a laicização ia de encontro às práticas discursivas dos tribunais da América hispânica e ao ideário que considerava, ainda no século XVIII, a possibilidade de um teólogo fazer o papel de jurista em um tribunal superior. Em Quito, por exemplo, um estudo sobre os argumentos utilizados nas

\footnotetext{
1 Paolo Grossi utiliza a expressão "absolutizar" sem as aspas e no mesmo sentido que utilizamos no presente artigo, ou seja, o de estabelecer relações com o Absolutismo. Os dicionários brasileiros, ao contrário, apenas constatam a palavra como uma variável do verbo "absolutizar", significando tornar algo absoluto (Grossi, 2014, p. 164-165, 190).
} 
petições entre 1650 e 1750 revelou que a fonte mais utilizada por advogados e procuradores, tanto em instâncias letradas como leigas, era a Bíblia, enquanto as leis do Reino eram pouco citadas. O Direito e a Teologia aparecem assim como duas facetas do mesmo saber (HERZOG, 1995, p. 905-911). E, ao contrário do que é possível visualizar para o mundo português, o estudo de Marcelo Rocha, Papéis Selados, apresenta um cenário de clericalização da justiça. Isso significa dizer que houve, ao menos desde a segunda metade do século XVII, o aumento do número de clérigos advogados e juristas em comparação com o número de leigos (2010, p. 21-22). Realidade que tem mais peso como estratégia interna da Igreja Católica do que como reflexo de uma política da Coroa para a formação dos seus advogados e juízes.

Portugal, da mesma maneira, conviveu por muito tempo com um processo de formação dos seus profissionais das leis que os deixava entre o mundo laico e religioso. Stuart Schwartz, no seu livro Burocracia e Sociedade no Brasil colonial, diz que, no século XVI, a Universidade de Coimbra já havia se tornado o "campo de treinamento do clero e da magistratura portuguesa". Tanto que ter habilitação em apenas uma das modalidades do Direito já era suficiente para a candidatura ao serviço régio (SCHWARTZ, 2011, p. 79-80). Situação semelhante ocorria no mundo hispânico. Para os chamados ofícios governativos, a exceção do cargo de vice-rei - lugar reservado para a alta aristocracia -, tornou-se cada vez mais necessária a formação jurídica, exatamente o maior bem que possuíam esses letrados, pelos seus estudos nas universidades castelhanas (MERLUZZI, 2017, posição 8592).

No quadro reformista, apesar da inserção no serviço régio dos recém-formados nas universidades, o Marquês de Pombal sinalizou para a necessidade de mudanças na educação portuguesa, referindo-se à tradição formativa da Universidade de Coimbra como "máximas depravadas". Para Carvalho e Melo, era necessário afastar a influência exercida pela Companhia de Jesus naquela Universidade. Logo, para não serem consideradas "depravadas" pelo principal ministro do rei $D$. José, o cotidiano formativo universitário precisava passar por uma reestruturação profunda. As reformas na Universidade de Coimbra, colocadas em curso no início da década de 1770, podem ser classificadas em função de dois objetivos: 1) fortalecer o caráter profissional dos magistrados e diplomatas; 2) e laicizar o processo de formação (SILVA, 2015, p. 424426). Estratégia que aparentemente deu resultado, visto o decréscimo, mesmo que leve, do número de formações em Direito Canônico a partir da segunda metade do século XVIII em Portugal (CAMARINHAS, 2016, p. 118-119).

Interessante notar que apesar da promoção de reformas para laicizar o ensino e a prática jurídica, o universo legal da Igreja de Roma teve papel fundamental para o desenvolvimento dos Estados modernos. O historiador norte-americano William J. Bouwsma no seu artigo Lawyers and Early Modern Culture, afirma que os formados em Direito Canônico, que nem sempre eram clérigos, foram importantes não apenas para a transformação do mundo medieval, senão igualmente importantes para o crescimento da complexidade social e institucional do mundo moderno (1973, p. 309-310).

Para além do uso das leis da Igreja no cotidiano e nos tribunais, a visão de haver certa sacralidade no trabalho dos juristas não era uma raridade. Esperava-se que o magistrado fosse capaz de adequar as normas às situações e, para que isso fosse feito de maneira proveitosa, deveria ele ser um exemplo de virtude e moral. Na obra Arte legal para estudiar la lurisprudencia, escrita no início do século XVII, o historiador, eclesiástico e jurisconsulto Francisco Bermúdez de Pedraza trata os juristas como verdadeiros religiosos, não pelo hábito, mas pelo espírito, já que deveriam no seu 
trabalho zelar pela equidade e pela justiça (ANZOÁTEGUI, 2016, p. 21). Os termos utilizados não são, de forma alguma, inocentes. Equidade (aequitas) é um conjunto harmônico de regras e institutos que pode ser vista nas próprias coisas, é parte da natureza delas. Deus, inclusive, pode ser classificado como equidade. E, quando os humanos se apropriam da equidade, ela se transforma em Justiça, gerando unidade entre o mundo dos fatos e o mundo das criações humanas (GROSSI, 2014, p. 171, 217220).

Acreditamos que tal aproximação não incomodava os letrados. A manutenção dos textos jurídicos em latim ou com expressões latinas, ainda que a maior parte estivesse em vernáculo, aparece como "projeto de poder". Não apenas por afastar das pessoas o entendimento fino do texto, mas, ajudava igualmente a associar as peças jurídicas ao mundo sacro (e dos saberes religiosos). Servia ainda para a manutenção das hierarquias profissionais no campo do Direito. Os juízes não letrados, como costumavam ser os juízes ordinários, por exemplo, seguiam mais o Direito Natural e Comum do que os compêndios universitários. E por isso, eram tratados pelos juízes letrados como executores do "direito dos rústicos" ou dos "direitos próprios" (consuetudinário) (HESPANHA, 2015, p. 376, 385). Ainda que havendo a necessidade de observar os códigos, como guia básico para os procedimentos, o casuísmo jurídico, prática comum na justiça dos reinos ibéricos e seus domínios ultramarinos, deixava as sentenças "à mercê do arbítrio do juiz". O que significa entender que o "justo encontrase não olhando para a lei e deduzindo-o a partir dela, mas olhando para a própria relação entre as partes", observando o que é justo entre elas e, só depois, "dizendo o direito de cada uma delas" (RUIZ, 2015, p. 104). No mesmo sentido, José de la Puente Brunke (2014) diz que

[...] la garantía de la justicia no estaba en las decisiones del juez, sino en su persona: si era un hombre bueno, prudente, con experiencia y conocedor de la tradición jurídica, había la seguridad de que iba a discernir adecuadamente justicia con referencia a cada caso concreto que tuviera que abordar, y finalmente de acuerdo con su conciencia.

Logo, tinha-se na figura dos magistrados a concentração das expectativas do Direito dito e chancelado em nome dos reis. Quadro agravado diante da mudança dos planos de ensino e, além disso, assistiu-se à suaves mudanças no perfil dos alunos do curso de Direito, o que provocou incomodo a uma aristocracia que também passou a buscar formação superior, sobremaneira do lado espanhol. Na região de Nova Espanha, por exemplo, o marquês Rodrigo Vivero afirmava que pelos seus cálculos, havia quase 70.000 estudantes nas universidades espanholas no início do século XVII, o que garantia um grupo numeroso de funcionários preparados para trabalhar, mas advertia que entre eles havia filhos de sapateiros e lavradores (MERLUZZI, 2017, p. 8614). Ou seja, valorizava o espaço formativo e a necessidade da formação, mas recaia nas amarras do lugar social do indivíduo, o que, no Antigo Regime, era definido pelo grupo de pertencimento.

Para Portugal, não é possível visualizar transformações bruscas no perfil dos alunos de Coimbra, nota-se, na verdade, a amplitude da presença de cada vez mais estudantes, quando observado o conjunto geral. Na realidade, desde o início do século XVII até a reforma de 1772, a quantidade de graduandos não para de crescer, dadas algumas peculiaridades que tornam os números ano a ano mais variáveis. Interessante ainda é que, dentro desse período, a presença de nascidos no Brasil também foi 
crescente (FONSECA, 1999, p. 533). Com mais homens vivendo a vida universitária, logo, havia mais pessoas prontas para os cargos com grau de especialidade técnica que foram sofrendo, sobremaneira ao longo do século XVIII, um processo de profissionalização e isso acaba refletindo na política régia para a entrada dos bacharéis na esfera do serviço do Estado.

\section{A "morte" dos letrados ou a reestruturação do serviço régio?}

O grupo privilegiado na nossa análise é aquele que servia ao Estado. Por isso, finalizamos o item anterior fortalecendo a ideia de uma categoria profissional de juízes que estava diretamente vinculada aos direcionamentos políticos tomados pelas Casas reinantes. No entanto, quando falamos sobre um grupo profissional para a realidade do século XVIII, precisamos ter cuidado para que este grupo não se confunda com a ideia existente hoje sobre os profissionais liberais que atuam na área do Direito. Tratamos aqui os magistrados como uma categoria profissional por ser necessária uma série de procedimentos para ter acesso ao serviço régio. No caso português, eles deveriam passar por um período de formação acadêmica, conquistando bacharelado ou licenciatura em Leis ou Cânones, curso comumente realizado na Universidade de Coimbra; ter de 01 a 02 anos de serviço nos auditórios antes da candidatura oficial ao serviço para dar entrada no processo de leitura dos bacharéis, realizado pelo Desembargo do Paço; após essa filtragem institucional, estando habilitado, o sujeito deveria esperar por sua primeira designação; conseguindo um lugar, ao menos dentro da retorica do período, deveria ter um tempo de serviço considerado como bom para a coroa e para partes, condição sempre presente nas cartas de nomeação. Ou seja, estamos observando uma dinâmica de atribuição de tarefas que exigia preparo técnico e boas relações nos lugares de serviço e na Corte. E, é exatamente nesse último ponto onde reside a chave para não os confundir com os profissionais liberais. As relações sociais que faziam as carreiras avançar ou não ainda estavam vinculadas aos princípios do Antigo Regime e ao lugar social dos indivíduos.

Já para àqueles que desejam servir os reis católicos de Castela, além de apresentar o diploma de formação universitária, também era necessário apresentar comprovação de tempo de serviço nos auditórios. Para os clérigos advogados, a apresentação dos títulos universitários, incluindo aí o desempenho acadêmico, era a porta de entrada para o recebimento de mercês, realidade válida também para os leigos. A segunda estratégia, que se aproxima do contexto luso, era a comprovação de bom procedimento em cargos públicos. O que acaba aparecendo não apenas como estratégia para o recebimento de mercês, mas, igualmente, como estratégia de manutenção na carreira da justiça. O que poderia ser facilitado pela boa relação com as pessoas que frequentavam a monarquia. Ter boas relações também internas, no próprio grupo de magistrados e advogados era fundamental. Nesse ponto, a tática dos grupos de formar redes de solidariedade podem ser vistas, intrafamiliar e extrafamiliar, em Portugal e na Espanha (ROCHA, 2010, p. 241, 42).

A introdução da questão familiar ampliou a procura pelos cargos no campo da justiça. Mesmo sendo pública a baixa taxa de permanência desses profissionais. O que pode, em parte, explicar o número crescente de nomeações em finais do século XVIII e início do XIX. Dados que levaram José Subtil a afirmar que a carreira na magistratura não era estável nem tampouco apetecível, apesar do número alto de candidaturas para o serviço. A Coroa portuguesa com frequência interrompia o tempo de serviço dos 
nomeados, mas tinha prontidão em tentar preencher novamente os cargos vagos, afinal, os magistrados eram os "delegados" da Coroa (SUBTIL, 2002, p. 41-54). Explicação que em nós reforça a ideia da importância dos magistrados como categoria profissional no serviço régio e mostra como as dificuldades não desanimaram algumas famílias que tomaram a função de dizer o direito em nome do rei como estratégia de estabilidade ou ascensão social. Nuno Camarinhas (2016, p. 19-20) diz que aparentemente não há relação entre as nomeações e as ligações familiares na carreira da justiça, mas quando vistos com cuidado os altos cargos, a relação aparece.

Antes de Camarinhas, Stuart Schwartz já havia percebido tal tendência, fazendo, inclusive, aproximações temporais quanto ao início do fenômeno. Os magistrados ganharam maior destaque no Reino de Portugal após as Cortes de Coimbra, em 1385. Daí para frente eles passaram a gozar de posição social equivalente à dos cavaleiros das ordens militares (2011, p. 34). Mesmo diante da equivalência, a busca pelos hábitos religiosos e militares fez parte da vida de diversos magistrados. Possuir um dos hábitos, inclusive, de maneira geral, aparece como estratégia de manutenção dos juízes na carreira ou foram utilizados como forma de facilitar o acesso ao serviço (OLIVAL, 1997, p. 69), visto que a leitura de bacharéis exigia também uma inquirição de genere para comprovar a limpeza de sangue e ausência de defeitos mecânicos. Com isso, os filhos dos letrados buscaram a mesma carreira e criaram certa dependência entre os serviços prestados pelos pais e o futuro sucesso profissional dos filhos. Fato é que famílias que buscavam afirmação social encontraram na magistratura a via mais segura e direta para a inserção dos seus parentes nas malhas da burocracia ${ }^{2}$ metropolitana e/ou colonial. Até mesmo porque fidalgos e a pequena nobreza militar eram obrigados a servir nas guerras e firmar posição pela manutenção dos seus privilégios, em oposição à expansão do poder real. Os magistrados, ao contrário, eram "filhos diretos" e "escolhidos" por esse crescimento (SCHWARTZ, 2011, p. 34-35).

A mesma máxima é válida para a Espanha, mas levou um pouco mais de tempo. O professor Manfredi Merluzzi diz que a vasta classe dos letrados nasceu das novas necessidades fruto do crescimento do aparelho burocrático da Monarquia Hispânica, tanto em território europeu como nas suas conquistas. Nessa gênese, ele já percebe um conflito aberto que se monta entre a alta nobreza e os letrados, a tempo dos Reis Católicos e, mais especificamente, no contexto das reformas colocadas em curso após as Cortes de Toledo, em 1480. E, não por coincidência, nesse período estava sendo montado o Conselho de Castela, parte fundamental de todo o aparato administrativo (MERLUZZI, 2017, p. 8582-8585). Logo, podemos perceber entre o século XIV e XV, na Península Ibérica, a convergência dos interesses das casas reinantes com os de um grupo de homens com a capacidade técnica exigida para tornar os planos de expansão de Portugal e Castela possíveis. Seguindo três séculos para frente, podemos mais uma vez observar nos mencionados reinos movimentos de reforma administrativa que mais uma vez mexem com um perfil técnico de funcionários e que torna a participação deles fundamental para o governo das gentes.

Os magistrados foram essenciais no desenvolvimento das instituições e das convenções da Europa Moderna. Inclusive quando vistos na longa duração. Pois, "é preciso entender que, no sistema jurídico de Antigo Regime, a autonomia de um direito não decorria principalmente da existência das próprias leis, mas, muito mais, da

\footnotetext{
2 Utilizamos aqui o conceito de burocratização baseado na leitura da WEBER, Max. Os Fundamentos da Organização Burocrática: uma construção do tipo ideal. In: CAMPOS, Edmundo (org.). Sociologia da Burocracia. $4^{a}$ ed. Rio de Janeiro: Zahar Editores, 1972. p. 15-28.
} 
capacidade local de preencher os espaços jurídicos de abertura ou indeterminação", o que aparece na "estrutura do direito comum". Até mesmo o chamado "direito das Índias", apenas recentemente, pelos trabalhos de Vítor Tau Anzoátegui, pode-se notar a construção desse direito pela prática, incluindo aí, determinadas práticas dos tribunais (HESPANHA, 2006, p. 95-96). No mesmo artigo, Hespanha é ainda mais claro em nota de roda pé, quando diz que os (2006, p. 104):

[...] valores políticos eram transformados em valores jurídicos porque o direito permitia que valores externos fossem recebidos em nome de conceitos genéricos [vazios, indeterminados], como "utilidade pública", "bem comum"; ou porque o direito reconhecia como jurídicos os valores já admitidos pelos dados da vida social ("posse de estado"); ou ainda porque o direito incorporava os condenados de uma razão natural acerca das relações humanas.

Na verdade, o Direito e os juristas foram, de maneira geral, importantíssimos não apenas em território europeu. Rapidamente, o continente americano pode sentir os reflexos da burocratização dos reinos ibéricos. A hierarquia cultural vigente na Europa buscava classificar os povos de acordo com as suas próprias "medidas". "Os africanos estavam no fundo da escala. Os asiáticos, em contrapartida, ocupavam o escalão intermédio, se bem que desvalorizados por caracterizações difusas, como 'a doença do turco', a 'feminilidade do indiano', a 'imobilidade do chinês'”. Balizados por esse tipo de classificação - que mais diz de quem classifica do que dos que são classificados -, definia-se, inclusive, o grau de autogoverno possível nas localidades (HESPANHA, 2001, p. 1202). Pois, entendemos aqui a cobertura jurídica oficial sobre determinadas matérias como sinal de um cuidado por parte do Estado. Visto que, não se legisla hábitos inexistentes. O que, por outro lado, não significa que as leis passavam automaticamente a povoar as relações sociais ou que eram respeitadas e acatadas sem qualquer tipo de questionamento. Ainda que, no século XVIII, o conjunto de reformas administrativas colocadas em curso pelos Bourbon na Espanha e pelos Bragança em Portugal tenha tentado estender os "braços" do Estado com mais vigor sobre os seus súditos.

As reformas pombalinas, em busca de dar caráter mais profissional ao serviço régio, adotou como uma das suas estratégias ampliar o seu alcance jurisdicional sobre os seus domínios ultramarinos. Para tal, foi necessário a criação de uma série de ouvidorias em regiões interioranas e o redesenho da abrangência das comarcas. Isso exigiu o aumento das nomeações para cargos nas ouvidorias e para os tribunais superiores. Logo, enquanto os lusos passam cada vez mais a investir na presença dos magistrados com grau elevado na hierarquia da administração da justiça, ainda que em lugares muito afastados da metrópole, os espanhóis fazem o movimento aparentemente contrário.

Havia no Reino de Castela uma tendência de diminuição das nomeações dos colegiales mayores, grupo privilegiado desde Las Siete Partidas. A redução do número de colegiales mayores entre os letrados espanhóis foi notada pelo historiador francês Jean-Pierre Dedieu e tratada por ele como a "morte do letrado". Por excelência, os letrados são para o autor os ministros do rei, vista a semelhança que havia entre as funções de ouvir e praticar a justiça. Mais especificamente, letrados eram os licenciados e doutores. Os advogados, bacharéis em Cânones ou Leis, tinham formação mais técnica e, por isso, eram vistos como "quase letrados". A história da administração real castelhana no século XVIII pode ser resumida, dentro dessa linha interpretativa, pela substituição do ministro (letrado) pelo oficial (secretário), o que fica bastante claro pela 
marginalização dos Conselhos ${ }^{3}$ (DEDIEU, 2005, p. 1-2, 11-13).

A historiadora Ana María Carabias Torres, no filão aberto por Dedieu, observa possibilidades desconsideradas ou pouco exploradas pelo francês. Para a autora, Dedieu foi conduzido ao erro quando considerou os colegiales mayores como os únicos letrados verdadeiros. No século XIII, chamava-se de letrado qualquer pessoa que fosse conhecedora de matérias científicas. Na centúria seguinte, aponta Maravall, a palavra já era utilizada como sinônimo de "advogado". Na legislação castelhana, o advogado aparece como alguém com formação universitária em Direito Civil ou Canônico. Alguns ordenamentos confirmam a equivalência entre os termos ao revelar que também eram chamados "letrados" aqueles que poderiam participar de pleitos nos tribunais. Onde Dedieu enxerga mais diferenças (grupos em conflito), Carabias Torres enxerga mais semelhanças (palavras diferentes para tratar da mesma ocupação) (2012, p. 149-154).

Ou seja, o que fundamentalmente se discute é um conceito para a palavra "letrado". Para Raphael Bluteau, "letrado" era o nome dado ao "homem ciente", "versado nas letras", "com ciência", "com erudição". Também não deixa de reafirmar a relação com os juristas e, especialmente os advogados (1716, p. 90). Enquanto isso, o dicionário mais importante para o mundo hispânico, o Diccionario de Autoridades, diz que o "letrado" é alguém douto nas letras (ciência) e, além de concordar com o uso do termo para os advogados, acrescenta características que podem ser tidas como comuns para essas pessoas: a discrição e a humildade ${ }^{4}$. Logo, temos para as duas definições traços semelhantes e que apontam para um grupo social internamente distinta entre si, abrangendo diversas áreas do conhecimento, e com uma diferença ainda mais profunda quando visto o conjunto social do período.

Além de uma marcante diferença na comparação com o tecido social, conforme acabamos de mencionar acima, não há como negar que em determinados momentos a diferenciação entre os cargos da própria justiça teve reflexos fortes na vida pessoal e profissional dos homens envolvidos nesse campo no Antigo Regime. Os advogados deveriam passar no seu processo formativo por universidades, ou seminários ou, no século XVIII, pelas Academias de Direito Real e Prático - que também ofereciam formação jurídica. Apesar da formação e da honra fruto dela, os advogados recebiam baixa remuneração e alguns tribunais ainda os impedia de entrar como participantes dos pleitos. Os juízes, por vezes, apenas poderiam utilizar os serviços de um advogado como assessoria jurídica (PERÉZ-PERDOMO, 2003, p. 557-558).

Por outro lado, os desembargadores, por ocuparem diversas funções em paralelo à justiça, conseguiam ter um tipo de penetração social que lhes garantia muitos privilégios. O impacto social que o desembargador tinha como indivíduo era grande. Os ganhos pessoais decorrentes da função eram consideráveis. Mas, o prestígio do sujeito não era comparável ao valor da assembleia reunida. Quando reunidos como "corpo" ou como "mesa", havia uma espécie de transfiguração dos indivíduos na própria autoridade. E, quando um desembargador deixava de ocupar o posto no Tribunal, ainda assim, preservava o prestígio e a forma de tratamento que tinha ainda no exercício do

\footnotetext{
${ }^{3}$ Em Portugal, também há um movimento de derrocada dos conselhos e avanço dos secretários, mas com características distintas daquelas apontadas por Jean-Pierre Didieu. Sobre o tema, ver BICALHO, Maria Fernanda; COSTA, André. O Conselho Ultramarino e a emergência do secretário de Estado na comunicação política entre reino e conquistas. In: Um reino e suas repúblicas no Atlântico: comunicação política entre Portugal, Brasil e Angola nos séculos XVII e XVIII / organização João Fragoso, Nuno Gonçalo Monteiro. Rio de Janeiro: Civilização Brasileira, 2017. p. 137-158.

4 DICCIONARIO DE AUTORIDADES (1726-1739). Tomo IV (1734). Verbete: letrado. Disponível em: < http://web.frl.es/DA.html>. Acesso: 15 de abril de 2019.
} 
cargo (SCHWARTZ, 2011, p. 247). Realidade muito distinta daquela apresentada para os advogados.

A resposta social aos advogados reforçava uma posição que tinha relação direta com as hierarquias internas da Justiça. Porém, uma coisa é diferença na preparação técnica e outra completamente diferente é a qualidade ou o estatuto. Pois, para as sociedades europeias de Antigo Regime, o indivíduo era, de certa forma, eclipsado pelas suas relações sociais. Isso significa dizer que as pessoas dependiam dos grupos sociais aos quais pertenciam e, cada grupo desempenhava funções específicas. Os direitos e deveres das pessoas, nesse cenário, estavam vinculados às funções (officium). Afinal, qualidade no Antigo Regime era uma "realidade jurídica decisiva, a verdadeira pessoa jurídica, era esse estado, que era permanente; e não os indivíduos, transitórios" (HESPANHA, 2015, p. 6226-6246).

Logo, qualquer associação de conceitos deve ser feita com bastante cuidado. Para entendermos melhor esta relação entre grupos que ora aparecem na historiografia como profissionalmente distintos, ora como equivalentes no trabalho, mas diferentes na posição social, consultamos o Diccionario de Autoridades. Pelos verbetes do dicionário se nota que havia no vocabulário castelhano a conservação da separação entre os níveis de preparo. O "colegio menor" é visto como uma comunidade de varões destinada ao estudo das ciências e governada por regras específicas. Os jovens que lá estudavam vestiam "el mismo manto, beca y bonete que los Colegiales mayores, aunque de distintos colores. Llámase menor, a diferencia del mayor, por no obligar a los que entran en él a hacer pruebas tan calificadas y rigurosas".

No entanto, quando o termo consultado é "colegio mayor" as provas qualificadas e rigorosas são reveladas: "llámase mayor, porque los sugetos que le componen, hacen pruebas rigurosas y mayores de limpieza de sangre y oficios para entrar en el: las quales se repútan por acto positivo, que los distingue y diferencia de los demás Colegios"6. Ou seja, antes de ser visto como grupo profissional, os colegiales mayores eram parte de um grupo socialmente bem articulado. E carregavam consigo o peso do lugar social como favorecimento às funções que exerciam. Pois,

[...] no es que la virtud se herede, pero el óptimo cuidador del jardín de la república hará bien en considerar los antecedentes familiares al crear magistrados, pues las virtudes del linaje, si no por la sangre, se transmiten por la costumbre y el ejemplo. Iguales las restantes condiciones, el perteneciente a linaje noble es más idóneo magistrado que el plebeyo. (VALLEJO, 1998, p. 28)

Logo, é possível entender que naquele ambiente cultural, os colegiales mayores carregavam desde o nascimento um conjunto de qualidades que os diferenciavam dos demais. Até mesmo porque o aparato judicial estava baseado na confiança dos pleiteantes. O que não significa confiança na justiça ou nas leis, senão confiança no "comportamento justo" dos juízes, que aparecia como "garantia moral" para tomar decisões livres e conscientes. Ou seja, uma justiça de certa maneira personalista, "de juízes, e não de 'leis"' (GARRIGA, 2013, p. 45). Daí o tempo de privilégios devotado aos colegiales mayores. O que não significa que a relação das grandes Casas do reino com a monarquia tenha sempre sido fácil, muito pelo contrário. As tensões existentes entre

\footnotetext{
${ }^{5}$ DICCIONARIO DE AUTORIDADES (1726-1739). Tomo II (1729). Verbete: colegio menor. Disponível em: <http://web.frl.es/DA.html>. Acesso: 13 de abril de 2019.

${ }^{6}$ DICCIONARIO DE AUTORIDADES (1726-1739). Tomo II (1729). Verbete: colegio mayor. Disponível em: <http://web.frl.es/DA.html>. Acesso: 13 de abril de 2019.
} 
os colegiales mayores e a monarquia refletiu na distribuição dos cargos. Enquanto em 1766 eles eram os responsáveis por $86 \%$ das praças da justiça, 13 anos depois, a influência que gozaram no passado estava praticamente extinta. O que não constitui, de forma alguma, o desaparecimento dessas famílias nobres. Diversos deles conseguiram se adaptar ao novo momento e reinventar a relação que mantinham com a monarquia, a administração e o exército (CARABIAS TORRES, 2012, p. 171-177).

Vista a dificuldade nessa relação, não é de se estranhar que o número de pessoas que se autodenominavam como "advogados" fosse crescente. E, apesar da temporalidade dos parágrafos acima estar vinculada a segunda metade do século XVIII, a "parceria" estabelecida entre a monarquia castelhana e os advogados é um fenômeno que remete ao início do século. Naquele período, os advogados tiveram mais acesso aos postos no Conselho de Castela e foi crescente também a tendência de nomear para a justiça senhorial pessoas vindas da advocacia. Para os Bourbons, na sua luta contra o ius commune, os advogados foram vistos como os parceiros ideais para essa empresa. Francisco de Castro, por exemplo, criticava no século XVIII o ensino de "leis mortas" e a falta de cuidado com as "leis vivas". Para ele, a felicidade do governo (bem estar social) passava pelo ensino das leis do Reino e, os que ainda assim, agiam de acordo com as normas do Direito Comum, mostravam o seu desprezo pela majestade (ALONSO ROMERO, 2012, p. 332-335, 457- 463).

Caso semelhante ao que acontecia em Portugal com os oficiais da justiça letrada. Semelhança que não está centrada no nível do discurso legal. Nos domínios lusos a estratégia de manter os corregedores e ouvidores no controle "transversal das jurisdições", letrada ou ordinária, deu resultado na medida em que eles realizavam esse trabalho utilizando métodos eruditos, ibéricos e europeus. Ou seja, mesmo havendo a sobrevivência e o uso do ius commune nos textos legais e nos tribunais portugueses, também havia espaço para o uso e execução das Leis do Reino. Nesse sentido, talvez tenha sido uma vantagem para os monarcas portugueses conseguirem muito cedo, pela impossibilidade de venalidade dos cargos da justiça, formar e manter a seu serviço grupos mais homogêneos culturalmente. $E$, a nomeação com intervalo trienal forçava a circulação desses profissionais e dificultava a patrimonialização dos ofícios (CAMARINHAS, 2016, p. 116). O que, ainda assim, não garantia a aplicação das leis de maneira rigorosa e irrestrita.

O impedimento ou a liberação da venalidade dos ofícios muito pode nos dizer sobre a ocupação dos cargos e o perfil das pessoas que os ocupavam. Conforme posto no parágrafo anterior, os portugueses conseguiram manter a Justiça mais afastada dessa prática. O jurista Rogelio Pérez-Perdomo diz que desde o século XVII até 1750 , alguns ofícios da justiça, como o cargo de ouvidor, eram passíveis de venda na América espanhola. A venda, no entanto, não significava desrespeito aos quesitos intelectuais mínimos para a ocupação do cargo, pode sim ter significado menor atenção aos detalhes. Pela proibição, a Coroa buscava ter mais controle político sobre os territórios coloniais e cortar os vínculos que os juízes pudessem ter com a sociedade local (PERÉZ-PERDOMO, 2003, p. 555-556). Outro desejo que, quando vista a prática, é fácil perceber os vínculos criados entre os juízes enviados pelas casas reinantes da Península Ibérica com os moradores das localidades. Os exemplos documentais para as duas realidades são vastos. Tanto é que, segundo Marcelo Rocha, os letrados espanhóis criaram laços entre si e costumaram usar os cargos em benefício próprio. Dentre os casos registrados, as denúncias de enriquecimento são as mais frequentes (2010, p. 42-43). 
Tais mudanças, para Dedieu, eram consequências da incapacidade da Coroa de controlar a sua própria administração. E, como forma de recuperar o seu domínio sobre os ofícios, criou instituições e para nelas servir colocou sujeitos maleáveis a vontade do rei. Tendo esta característica no horizonte, a Coroa buscou transferir funções sem romper as bases do pacto político vigente (DEDIEU, 2005, p. 22). A relação dos governos centrais ou metropolitanos com os habitantes das colônias precisava ser cuidada, para evitar indisposições que pudessem vir a ser inegociáveis. Os entraves impostos aos criollos, por exemplo, que os impedia de ocupar determinados cargos da administração pública, aumentaram as suas frustrações como extrato social e pode estar entre as razões que alimentaram as independências no século XIX (PERÉZPERDOMO, 2003, p. 584). Ainda assim, tal visão que antecipa os eventos do século XIX, acaba por desconsiderar fatores importantes, para além do descontentamento do criollos em relação aos espaços ocupados no seio da justiça, e acaba por vincular diretamente fatos que por si exigem tratamento mais complexo.

Pontuando exatamente sobre o aspecto reformista adotado pelos reis católicos, Carlos Garriga (GARRIGA, 2013, p. 56) mostra que:

[...] para conhecer o impacto que tiveram as reformas bourbônico nas Audiencias (e, por extensão, sobre as sociedades) americanas do Setecentos não importa tanto conhecer a proporção entre criollos e peninsulares no seio dos tribunais, mas, sim, indagar como e em que medida se conseguiu evitar a imbricação dos juízes na sociedade local. Não parece prudente ter muitas ilusões a respeito, tendo em conta a abundância de testemunhos em contrário. Nestas condições, sintetizar o Reformismo bourbônico em termos como "centralização" resulta, no mínimo, inapropriado, como a seu tempo alguns coevos não deixaram de advertir. Ao final, se algo demonstra a experiência do reformismo bourbônico no âmbito da justiça é a impossibilidade de impor a vontade real ao aparato instituído para administrá-la.

Dito de outra forma, o autor não vê para o período os Bourbon com a força necessária para exercer a sua autoridade de forma imperativa, ainda que tomem medidas nesse sentido. Para sermos analiticamente mais justos, a questão central não está de fato no poder da monarquia, senão nas características daquilo que era entendido como "governo" no Antigo Regime e das circunstâncias próprias dessa organização social. Até mesmo porque os propósitos da política régia não seguiam caminhos coerentes. Muito pelo contrário. Um mesmo rei ou rainha poderia chancelar leis absolutamente contraditórias ou com caráter temporário desde a partida, quando, por exemplo, finalizava-se uma lei ou ordem com a frase "até que se mande o contrário". $\mathrm{E}$, para o contexto da época, isso não aparece como um problema. Pois, não havia a ilusão do cumprimento integral das medidas adotadas (GARRIGA, 2013, p. 41-42). O que mostra muito bem a consciência coeva sobre os poderes negociados e as maneiras de garantir a governabilidade dos lugares. Já que, apesar das tentativas, tanto em Portugal como na Espanha, de dar maior unidade ao ordenamento jurídico vigente, a pluralidade dos estatutos ainda era considerável no século XVIII e, nenhum desses estatutos, aspirava regular a sociedade de forma exclusiva (HESPANHA, 2001, p. 1197).

\section{Considerações finais}

Conforme apontado até aqui, havia para os reinos ibéricos certa proximidade entre as suas leis e agentes com funções semelhantes. No entanto, nos chama especial atenção no século XVIII o movimento de vinculação entre as principais ações em cada um dos reinos e o maior ou menor relevo dado aos magistrados pelas Coroas. O ponto 
fundamental para entender essa relação é a historicidade de cada período estudado. A História não se repete e a maneira de tratar e inserir os juízes no serviço régio reflete o momento de cada um dos Reinos. Ainda que as experiências se encontrem no desejo dos Bourbon e dos Bragança de consolidar uma forma de governo através da qual o Estado tenta tomar para si as rédeas do corpus literário. Temática que já aparece na historiografia com luzes sobre essa capacidade ou incapacidade de concentrar as ações e com a margem sempre aberta para uma operação governativa negociada.

Portugal, logo quando os juristas ganharam mais espaço junto ao poder positivo (político), não dependeu das grandes Casas portuguesas para cobrir juridicamente os lugares e as pessoas. O plano de expansão, dessa forma, pode ser seguido fazendo com que os "delegados" do rei fossem enviados para as mais diversas partes do Império. A circulação desse corpo de profissionais, consideravelmente homogeneizado do ponto de vista da formação pela Universidade de Coimbra, os fazia entrar em contato com realidades muito diversas e exigia deles capacidade de adaptação para lidar com os hábitos locais e, principalmente, com outros ordenamentos jurídicos, aos quais não se dava acesso pela via universitária. O papel de Coimbra, na realidade, ia mais além das questões científicas. A já mencionada experiência de socialização e lealdade à monarquia era tão ou mais importante do que os estudos. $E$ foi tendo esse processo de formação/socialização, circulação e tolerância à determinadas práticas desviantes por matriz que a relação entre a Casa de Bragança e os seus magistrados se desenvolveu. No contexto do século XVIII, inclusive, um plano de reforma dos estatutos da Universidade de Coimbra, uma das prioridades do Marquês de Pombal, foi implementado no intuito de adequar os currículos à Europa iluminista e afastar a Companhia de Jesus das diretrizes do aprendizado. As mudanças postas em curso na segunda metade do século XVIII, na forma e no conteúdo das aulas régias, a exemplo das primeiras letras, como também o que foi feito na Universidade de Coimbra, possibilitaram, mesmo sob a tutela da monarquia, um momento de oxigenação e/ou renovação das ciências de maneira geral (CONTI, 2018, p. 414). E, em especial, da Filosofia e do Direito.

Já no que diz respeito ao processo espanhol, não acreditamos que a necessidade de reconfiguração do pacto entre monarquia e os magistrados tenha surgido como consequência de déficits formativos. Os especialistas mencionados anteriormente conseguem mostrar uma Universidade de Salamanca (parâmetro de conduta para as demais) muito bem articulada com as necessidades e a tradição jurídica do mundo hispânico. A mudança não foi provocada por questões técnicas, senão pelo choque existente entre a Casa de Bourbon e o núcleo da nobreza espanhola que ocupava os postos na administração da justiça. Não sendo interesse da Casa reinante a manutenção de uma relação conflituosa, ela pode se valer daqueles que por muito tempo estiveram à margem da hierarquia interna do campo do Direito e, que ainda viam na carreira da justiça, uma oportunidade para ascender socialmente, especialmente nas áreas coloniais, mas também em território europeu.

Como señalaba Braudel, los letrados ocuparon siempre más espacios en posiciones de influencia en la escena política, favoreciendo el ascenso social de esta capa social. Según el historiador francés, estos funcionarios, llamados al poder, no tardaron en 'acaparar una parte de la autoridad pública'. Paralelamente, la Corona pretendió despojar a la alta nobleza de sus características feudales y guerreras, induciéndola a asumir funciones cortesanas, burocráticas y, solo en ocasiones, militares, 'transformando al gran señor feudal en un funcionario militar'. Tales 
dinámicas sociales no escaparon de la alta nobleza castellana, creándose así naturalmente las bases de un fuerte resentimiento, como parece indicar el despreciativo testimonio de un defensor de la alta aristocracia, Diego Hurtado de Mendoza, quien apunta en su Guerra de Granada: 'Los Reyes Católicos han puesto la administración de justicia y de los asuntos públicos en manos de los letrados, gente de condición media, ni grandes, ni pequeños, no causantes de agravio ni a unos ni a otros, y cuya profesión era el estudio del derecho'. (MERLUZZI, 2017, p. 8600-8608)

Logo, a figura do letrado não desaparece das sociedades hispânicas e portuguesas, muito pelo contrário. Há um aprofundamento da participação das pessoas com grau superior de formação na vida pública. Inclusive, o papel desempenhado pelos magistrados no processo de legitimação das independências (ainda que não tenha havido unanimidade, inclusive na historiografia sobre o tema) na América Latina foi muito importante. O que mostra a penetração social desse grupo para além da convivência governativa com as casas reinantes do século XVIII. E, se pararmos para analisar o espaço e a força dos magistrados na organização da vida social nessas áreas, poderemos perceber que mesmo após a adoção da ideia da divisão dos poderes, o campo administrativo, espaço dos "burocratas", foi também ocupado em diversos momentos por bacharéis e licenciados em Leis ou Cânones. A "profissionalização" da administração dos reinos e domínios ultramarinos, resultado de um conjunto maior de reformas realizado, principalmente durante os reinados de D. José em Portugal e Carlos III na Espanha, foi acompanhada pelo avanço do processo de "profissionalização" e formação de redes de colaboração entre os letrados. O que não significou o seu desaparecimento, senão a reestruturação das estratégias de manutenção e ascensão social ligadas a uma carreira dizendo o direito em nome d'El Rey.

\section{Referências}

ALONSO ROMERO, María Paz. Salamanca, escuela de juristas: Estudios sobre la enseñanza del derecho en el Antiguo Régimen. Universidad Carlos III de Madrid. Editorial Dykinson, 2012. Disponível em: <http://hdl.handle.net/10016/15129>.

ANZOÁTEGUI, Víctor Tau. El Jurista en el Nuevo Mundo. Pensamiento. Doctrina. Mentalidad. Global Perspectives on Legal History, Max Planck Institute for European Legal History Open Access Publication, Frankfurt am Main, 2016. Disponível em: <http://dx.doi.org/10.12946/gplh7>.

BLUTEAU, Rafael, 1638-1734. Vocabulario Portuguez e latino (Volume 05: Letras K-N). Lisboa: Officina de Pascoal da Sylva, Impressor de Sua Magestade, 1716. Disponível em: <http://dicionarios.bbm.usp.br/pt-br/dicionario/1/letrado>.

BOUWSMA, William J. Lawyers and Early Modern Culture. In: The American Historical Review, vol. 78, no. 2, 1973, pp. 303-327. DOI: 10.2307/1861170.

CAMARINHAS, Nuno. Administração da Justiça em espaços coloniais. A experiência imperial portuguesa e os seus juízes, na época moderna. In: Jahrbuch für Geschichte Lateinamerikas - Anuario de Historia de America Latina. Volume 52, Issue 1, Pages 109-124, ISSN (Online) 2194-3680, May 2016. DOI: https://doi.org/10.7767/jbla-20150107.

CARABIAS TORRES, Ana María. "¿La muerte del letrado? Consideraciones sobre la tipología del oficial español en el siglo XVIII", en Salustiano de Dios Y Eugenia Torijano 
(coords.), Cultura política y práctica del derecho. Juristas de Salamanca siglos XV-XX. Salamanca: Ediciones Universidad de Salamanca, 2012, pp. 143-238. Disponível em: <https://gredos.usal.es/jspui/bitstream/10366/124008/1/DHMMC_CarabiasTorres_Muer te_Letrado_tit_2012.pdf>.

CONTI, Paulo Fillipy de Souza. A Ilustração tardia em Portugal e os espaços de sociabilidade intelectual em Pernambuco. Tempos Históricos, Volume $22,2^{\circ}$ Semestre de 2018, p. 402-432. e-ISSN: 1983-1463. Disponível em: <http://erevista.unioeste.br/index.php/temposhistoricos/article/view/19348>.

DEDIEU, Jean-Pierre. La muerte del letrado. Aranda Pérez (Francisco José). Letrados, juristas y burócratas en la España moderna, Universidad de Castilla y León, pp. 479512, 2005. Disponível em: <https://halshs.archives-ouvertes.fr/halshs-00004670>.

DICCIONARIO DE AUTORIDADES (1726-1739). Tomo II. Real Academia Española, 1729. Disponível em: <http://web.frl.es/DA.html>.

FONSECA, Fernando Taveira da. Scientiae thesaurus mirabilis: estudantes de origem brasileira na Universidade de Coimbra. Revista Portuguesa de História, t. XXXIII (1999).

GARRIGA, Carlos. Os limites do reformismo bourbônico: a propósito da administração da justiça na América espanhola. Almanack, Guarulhos, n. 6, p. 38-60, Dec. 2013. Disponível em: <http://www.scielo.br/scielo.php?script=sci_arttext\&pid=S223646332013000200038\&lng=en\&nrm=iso>. Acesso em 23 Nov. 2019. http://dx.doi.org/10.1590/2236-463320130604.

GROSSI, Paolo. A ordem jurídica medieval / Paolo Grossi; tradução de Denise Rossato Agostinetti; revisão técnica de Ricardo Marcelo Fonseca. - São Paulo: Editora WMF Martins Fontes, 2014.

HESPANHA, António Manuel. Os juristas como couteiros. A ordem na Europa ocidental dos inícios da idade moderna. In: Análise Social, vol. XXXVI (161), 2001, 1183-1208.

HESPANHA, António Manuel. Direito comum e direito colonial. Panóptica, Vitória, ano 1, n. 3, nov. 2006, p. 95-116. Disponível em: <http:www.panoptica.org>. Acesso em: 25 Nov. 2019.

HESPANHA, António Manuel. Como os juristas viam o mundo (1550-1750): Direitos, estados, pessoas, coisas, contratos, ações e crimes. Lisboa: CreateSpace Independent Publishing Platform (Edição Kindle), 2015.

HERZOG, Tamar. Sobre la cultura jurídica de la América colonial (siglos XVI-XVIII). In: Anuario de historia del derecho español, ISSN 0304-4319, № 65, 1995. pp. 903-912. Disponível em: <https://dialnet.unirioja.es/descarga/articulo/134634.pdf>.

MARAVALL, José Antônio. La formación de la conciencia estamental de los letrados. In: Revista de Estudios Políticos, ISSN 0048-7694, № 70, 1953, págs. 53-82. Disponível em: <https://dialnet.unirioja.es/descarga/articulo/2128916.pdf>.

MERLUZZI, Manfredi. La Audiencia de Lima entre la administración de justicia y las luchas políticas por el control del Virreinato (siglo XVI). In: CASELLI, Elisa (coord.). Justicias, agentes y jurisdicciones. De la Monarquía Hispánica a los Estados Nacionales (España y América, siglos XVI-XIX) (Historia) (Spanish Edition). (2017) Fondo De Cultura Económica De España, S.L. Edição do Kindle. 
OLIVAL, Fernanda. O acesso de uma família de cristãos-novos portugueses à Ordem de Cristo. Ler História, 33 (1997), 67-82.

PÉREZ-PERDOMO, Rogelio. Los abogados americanos de la monarquía española. Anuario Mexicano de Historia del Derecho, ISSN-e 0188-0837, №. 15, 2003, págs. 545$600 . \quad$ Disponível em: <https://revistascolaboracion.juridicas.unam.mx/index.php/anuario-mexicano-historiader/article/download/29659/26782>.

PUENTE BRUNKE, José de la (2014). La Real Audiencia de Lima, el sello real y la garantía de la justicia. Revista de Humanidades [en línea], n. 22, artículo 9, ISSN 23408995. Disponível em <http://www.revistadehumanidades.com/articulos/75-la-realaudiencia-de-lima-el-sello-real-y-la-garantia-de-la-justicia>. Consulta em 26 Nov. de 2019. DOI: http://dx.doi.org/10.5944/rdh.22.2014.14296

ROCHA, Marcelo. Papéis Selados: carreira jurídica, estratégias de reputação e poder na Nova Espanha (1580-1730) / Marcelo Rocha. - Rio de Janeiro: Mauad X; Faperj, 2010.

RUIZ, Rafael. O sal da consciência: probabilismo e justiça no mundo ibérico - São Paulo: Instituto Brasileiro de Filosofia e Ciência "Raimundo Lúlio" (Ramon Llull), 2015.

SCHWARTZ, Stuart B. Burocracia e sociedade no Brasil colonial: o Tribunal Superior da Bahia e seus desembargadores, 1609-1751. São Paulo: Companhia das Letras, 2011.

SILVA, Ana Rosa Cloclet da. O Marquês de Pombal e a formação do homem-público no Portugal setecentista. In: A "Época Pombalina" no mundo luso-brasileiro / Francisco Falcon, Claudia Rodrigues (Org). Rio de Janeiro: Editora FGV, 2015.

SUBTIL, José. Os ministros do rei no poder local, ilhas e ultramar (1772-1826). Penélope, $\quad \mathrm{n}^{0} 27, \quad 2002, \quad$ p. 37-58. Disponível em: $<$ http://repositorio.ual.pt/bitstream/11144/2513/1/Os\%20Ministros\%20do\%20Rei\%20no \%20Poder\%20Local\%252c\%20llhas\%20e\%20Ultramar.pdf>.

VALLEJO, Jesús. Acerca del fruto del árbol de los jueces. Escenarios de la Justicia en la cultura del ius commune. In: AFDUAM 2 (1998), pp. 19-46. Disponível em: $<$ http://hdl.handle.net/11441/53401>.

\section{Notas de autoria}

Paulo Fillipy de Souza Conti é doutorando pelo Programa de Pós-Graduação em História da UFPE, onde desenvolve tese sob orientação da Prof. ${ }^{a}$ Dr. $^{a}$ Virgínia Maria Almoêdo de Assis. Membro do Núcleo de Estudos do Mundo Atlântico (NEMAt) e do grupo de pesquisa do CNPq "O Mundo Atlântico". Bolsista da Capes. E-mail: paulofconti@gmail.com.

\section{Como citar esse artigo de acordo com as normas da revista}

CONTI, Paulo Fillipy de Souza. Os Magistrados e as Monarquias Ibéricas no século XVIII. Sæculum - Revista de História, v. 24, n 41, p. 64-81, 2019.

\section{Contribuição de autoria}

Não se aplica.

\section{Consentimento de uso de imagem}

Não se aplica. 
Aprovação de comitê de ética em pesquisa

Não se aplica.

\section{Licença de uso}

Este artigo está licenciado sob a Licença Creative Commons CC-BY. Com essa licença você pode compartilhar, adaptar, criar para qualquer fim, desde que atribua a autoria da obra.

\section{Histórico}

Recebido em 31/05/2019.

Aprovado em 06/09/2019. 